\title{
Varieties of entailment: introduction to the special issue
}

\author{
Heinrich Wansing ${ }^{1}$ (D) Marco Ruffino ${ }^{2}$
}

Received: 2 February 2020 / Accepted: 2 July 2020 / Published online: 13 July 2020

(c) The Author(s) 2020

This special issue of Synthese is dedicated to the memory of Carolina Blasio da Silva, a young and talented Brazilian logician, who sadly left this world too early, only one day after successfully defending her Ph.D. thesis on non-classical forms of entailment at the University of Campinas, Brazil, on August 25, 2017. Carolina originally studied Psychology and Philosophy at the Federal University of Juiz de Fora, Brazil, and did her MSc on Heidegger and the question of time. She did part of her undergraduate studies in Passau, and spent time as a visiting researcher, during her graduation period, at Tel-Aviv University, King's College London, Vienna University of Technology, the University of Lisbon, and Ruhr University Bochum. She was the administrator of the Brazilian discussion group on Logic, an active member of the Brazilian LaTeX community, and a feminist campaigner.

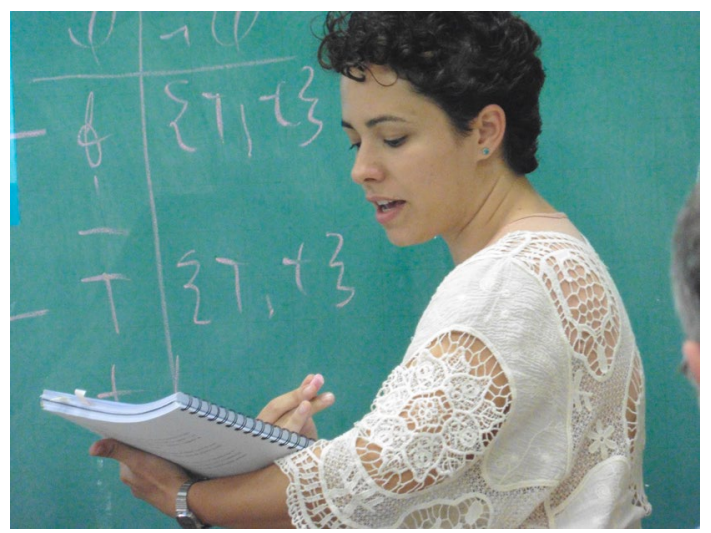

Heinrich Wansing

Heinrich.Wansing@rub.de

Marco Ruffino

ruffinomarco@gmail.com

1 Department of Philosophy I, Ruhr University Bochum, 44780 Bochum, Germany

2 Department of Philosophy, UNICAMP, Rua Cora Coralina 100, Cidade Universitária, Campinas, SP CEP 13083-896, Brazil 
Before her untimely death, Carolina was working intensively on a many-dimensional notion of logical consequence and generalized logical values related to that conception. She did so not just in her dissertation, but also in several papers (some of them already published and some about to be submitted). For those who had the fortune to know her, it was at the same time lovely and inspiring to see Carolina being both an active young researcher and a caring mother in the many international conferences on logic and philosophy to which she brought her baby daughter. Carolina's enthusiasm and intellectual love for her work were contagious, as was her sympathy, personal charisma, and generosity, and we are grateful for her legacy both as a philosopher and as a human being. She is survived by her logician husband, João Marcos, and their daughter, Maia.

We here give a brief description of the contributions to this special issue.

The notion of a Tarskian consequence relation has been playing a central role in theorizing about logical consequence and still is the conception against which different or generalized notions of logical consequence are compared. A certain generalized notion of logical consequence has emerged in proof-theoretic semantics, where provability is seen as a kind of warranted assertability. It has been suggested to consider the speech act of assertion to be on a par with the speech act of denial, thereby arriving at bilateral proof systems that comprise rules for both proving and refuting formulas. In his paper "Tarskian consequence relations bilaterally: some familiar notions," Sergey Drobyshevich introduces signed consequence relations as a bilateral variant of Tarskian consequence relations. He presents David Nelson's paraconsistent logic N4 with strong negation as a bilateral natural deduction system in sequent form and investigates bilateral variants of the notions of a fragment of a consequence relation, definitional equivalence, and conservative extension.

A defining feature of Tarskain consequence relations is their transitivity. In sequent calculi, transitivity is implied by the admissibility of the cut rule. Yaroslav Shramko and Heinrich Wansing in their paper "The nature of entailment: an informational approach," introduce and discuss what they call the "Ackermann principle" of entailment. They obtain a transitive, bilateral notion of entailment as a relation between the positive and negative informational contents of sentences, respectively sets of sentences.

The conception of a logic as a single consequence relation is also challenged by Eduardo Barrio, Federico Pailos, and Damian Szmuc in their contribution "(Meta) Inferential Levels of Entailment Beyond the Tarskian Paradigm." Starting from substructural logics, they consider not only logical consequence between formulas or sets of formulas but also "metainferences", i.e., inferences between inferences. They suggest that a logic ought to be identified with an infinite sequence of consequence relations of increasing levels of nesting. We may note that a nesting of the sequent arrow so as to obtain a higher-level conception of logical consequence has already been suggested in not very well known works by the German philosopher Franz von Kutschera (1968, 1969).

Rohan French and David Ripley in their "Two Traditions in Abstract Valuational Model Theory" compare two approaches to non-transitive and non-reflexive, and hence non-Tarskian consequence relations. One approach, which they call "the Galois tradition," emphasizes the role of a Galois connection between consequence 
relations and sets of bivaluations. In order to present the other approach, they define the notion of a Malinowski valuation, giving rise to what they call "the Malinowski tradition."

Emmanuel Chemla and Paul Egré's contribution "From Many-Valued Consequence to Many-Valued Connectives" also focuses on a generalization of Tarskian consequence relations, namely multi-premise and multi-conclusion intersective mixed consequence relations. The authors consider three- and four-valued logics and state necessary and sufficient conditions for the existence of so-called Gentzen-regular connectives that are definable for the consequence relations under consideration.

The paper "Quasi-canonical Systems and Their Semantics" by Arnon Avron is an investigation into quasi-canonical Gentzen-type sequent calculi. Such proof-systems are particularly suited for extensions of Belnap and Dunn's four-valued logic known as first-degree entailment logic (FDE) such as the already mentioned logic N4. Avron shows that a quasi-canonical system is coherent just in case it is analytic and just in case it has a characteristic non-deterministic matrix based on some subset of the set of the four truth-values used in the semantics for FDE.

Sérgio Marcelino and Carlos Caleiro in their paper "Axiomatizing non-deterministic many-valued generalized consequence relations" tie in with Avron's investigation of the relationship between non-deterministic matrices and logical consequence by studying the axiomatization of generalized, multiple-conclusion consequence relations determined by such matrices. They show that for finite non-deterministic matrices one can find finite axiomatizations with a generalized subformula property.

Intuitionistic logic is widely seen a one of the most important alternatives to the system that is nowadays known as classical logic. Elaine Pimentel, Luiz Carlos Pereira, and Valeria de Paiva in their paper "An Ecumenical Notion of Entailment" consider the combination of classical and intuitionistic predicate logic in a single unified proof system. Taking up work by Dag Prawitz, they present an "ecumencial" sequent calculus and study its proof-theoretic properties such as cut-elimination.

In his paper "Obtaining infinitely many degrees of inconsistency by adding a strictly paraconsistent negation to classical logic," Peter Verdée studies an entailment relation for a language that contains both Boolean negation and a paraconsistent negation based on the logic of paradox (LP). Moreover, this logic (CLP) satisfies in addition to being a conservative extension of both classical logic and LP two other properties Verdée takes to be desirable for property theoretic applications. The system CLP is presented axiomatically and in terms of three different equivalent semantics, including an infinite-valued semantics with integer numbers as values.

In their "Measuring evidence: a probabilistic approach to an extension of BelnapDunn Logic" Abílio Rodrigues, Walter Carnielli, and Juliana Bueno-Soler introduce a logic of evidence and truth conceived as an extension of Belnap-Dunn's four-valued logic. This is an improved version of a logic previously introduced by Carnielli and Rodrigues (2017) that was equipped with a classicality operator. The new logic is equipped both with a classicality and a non-classicality operator (here conceived as dual operators). The authors propose a probabilistic semantics for this new system and re-interpret some known theorems of standard probability theory. 
Carolina Blasio (to whom this issue is dedicated), João Marcos, and Carlos Caleiro's "What is a logical theory? On theories containing assertions and denials" seek to overcome what they consider to be a bias of most logical theories of inference towards assertions, and propose a theory that deals with the interplay between acceptance and rejection of sentences or utterances in various contexts. They develop a conceptual framework for this task, and discuss several aspects of the theory of compatibility relations as e.g. the lattice of these relations, Galois connections, finitaryness, consistency, etc.

In "Logic without Metaphysics" José Zalabardo proposes an alternative approach (that he characterizes as holistic in opposition to the traditional atomistic approaches) for defining logical consequence for formal languages. This new approach dispenses with the assignment of values to the extra-logical constants of formal languages (i.e., it goes without appealing to models). Zalabardo shows how to apply this approach to first-order (both non-modal and modal) logic.

In their "Knot is not that nasty (but it is hardier than tonk)", Elisángela RamírezCámara and Luis Estrada-González evaluate Tim Button's (2016) claim that the knot operator is nasty (in the sense that adding it to the set of classical operators provides counterexamples to a number of classically valid operational rules in a sequent calculus proof system). They discuss a problem for model-theoretic accounts of the connective knot that is supposedly analogous to the problem caused by tonk for inferentialist accounts of connective meaning and argue that dropping some features of the knot operator makes it not as nasty as Button claims.

In her "Conservative translations of four-valued logics in modal logic" Ekaterina Kubyshkina proposes, as the title indicates, a Translation Manual of every truthfunctional four-valued logics into modal logic, very much in the spirit of Barteld Kooi and Allard Tamminga's previous work (2013). She also introduces some novelties of her own into their model to preserve the intuitive readings of some truthvalues for every four-valued logic and then proves the manual's conservativeness (alias faithfulness).

In "Psychophysiological approach to the Liar sentence. Jean Buridan's virtual entailment principle put to test" Konrad Rudnicki and Piotr Łukowski present an experiment to examine brain activity in response to true sentences, false sentences, and self-referential sentences (including the Liar and the Truthteller). The results indicate that the Liar sentence is processed by the human brain identically to false sentences. This seems to provide empirical evidence for the virtual entailment principle (originally proposed by Jean Buridan) which solves the Liar paradox by taking it to be a false sentence.

In "Contingent A Priori Truths and Performatives" Marco Ruffino proposes a new approach to Kripke's classic cases of contingent a priori truths (presented in Kripke (1980)) in terms of the illocutionary force involved in generating them. The idea is that the illocutionary acts involved in stipulations must involve a performative verb and, hence, be an instance of what Searle and Vanderveken (1985) call a declarative act. Declarative acts have two very special features: on the one hand, they must have a contingent propositional content and, on the other hand, if successful, they bring about the fact represented in the propositional content. 
Acknowledgements Open Access funding provided by Projekt DEAL. We are grateful to the editors-inchief of Synthese for supporting the project of a tribute to Carolina Blasio da Silva, to the scholars who submitted their contributions, and to the reviewers who helped us in the preparation of this special issue.

Open Access This article is licensed under a Creative Commons Attribution 4.0 International License, which permits use, sharing, adaptation, distribution and reproduction in any medium or format, as long as you give appropriate credit to the original author(s) and the source, provide a link to the Creative Commons licence, and indicate if changes were made. The images or other third party material in this article are included in the article's Creative Commons licence, unless indicated otherwise in a credit line to the material. If material is not included in the article's Creative Commons licence and your intended use is not permitted by statutory regulation or exceeds the permitted use, you will need to obtain permission directly from the copyright holder. To view a copy of this licence, visit http://creativecommons.org/licen ses/by/4.0/.

\section{References}

Button, T. (2016). Knot and tonk: Nasty connectives on many-valued truth-tables for classical sentential logic. Analysis, 76(1), 7-19.

Carnielli, W., \& Rodrigues, A. (2017). An epistemic approach to paraconsistency: a logic of evidence and truth. Synthese, 196, 3789-3813.

Kooi, B., \& Tamminga, A. (2013). Three-valued Logics in Modal Logic. Studia Logica, 101, 1061-1072. Kripke, S. (1980). Naming and Necessity. Harvard University Press.

Searle, J., Vanderveken, D. (1985). Foundations of Illocutionary Logic. Oxford University Press.

von Kutschera, F. (1968). "Die Vollständigkeit des Operatorensystems $\{\neg, \wedge, \vee, \supset\}$ für die intuitionistische Aussagenlogik im Rahmen der Gentzensemantik. Archiv für mathematische Logik und Grundlagenforschung, 11, 3-16.

von Kutschera, F. (1969). Ein verallgemeinerter Widerlegungsbegriff für Gentzenkalküle. Archiv für mathematische Logik und Grundlagenforschung, 12, 104-118.

Publisher's Note Springer Nature remains neutral with regard to jurisdictional claims in published maps and institutional affiliations. 